\title{
Survivin mRNA Antagonist EZN-3042
}

National Cancer Institute

\section{Source}

National Cancer Institute. Survivin mRNA Antagonist EZN-3042. NCI Thesaurus. Code C92578.

A locked nucleic acid (LNA) antisense oligonucleotide targ eting survivin mRNA, with potential antineoplastic activity. EZN-3042 hybridizes to survivin mRNA, thereby blocking translation of survivin protein and inhibiting survivin-induced anti-apoptotic activity and promoting tumor cell apoptosis in survivin-overexpressing tumor cells. Survivin, a member of the inhibitor of apoptosis (IAP) family expressed during embryonic development, is upregulated in a variety of human cancers while absent in most normal adult cells; its expression in tumors is associated with a more aggressive phenotype, decreased survival, and increased resistance to chemotherapy. LNAs contain a methylene bridge linking 2'-oxygen and 4'-carbon of ribose sugar rings, thereby increasing their stability and decreasing degradation. 